\title{
ANÁLISE DOS GASTOS DE UMA INSTITUIÇÃO FEDERAL NA EDUCAÇÃO DE ENSINO SUPERIOR DOS ANOS DE 2015 A 2017
}

\author{
ANALYSIS OF THE EXPENDITURE OF A FEDERAL INSTITUTION IN \\ HIGHER EDUCATION FOR THE YEARS FROM 2015 TO 2017
}

\author{
Ketlen Menezes Couto ${ }^{1}$ \\ Leonor Bernadete Aleixo dos Santos ${ }^{2}$ \\ Bartolomeu Miranda Pereira ${ }^{3}$ \\ Miguel Carlos Viana Negreiros ${ }^{4}$
}

1.

Bacharel em Ciências

Contábeis pela Universidade

Federal do Amazonas.

2.

Mestre em Contabilidade

e Controladoria pela

Universidade Federal do

Amazonas, Professora de

Ciências Contábeis pela

Universidade Federal do

Amazonas, especialista em

Auditoria Interna e Externa.

3.

Doutorando em

Administração pela UEA e

Mestre em Contabilidade e

Controladoria pela UFAM

(2014). pós-graduado

pela Fundação Getulio

Vargas no Curso de MBA

em Gerenciamento de

Projetos (2004), graduado

em Ciências Contábeis

pela Universidade Federal

do Amazonas (2011).

4.

Mestre em Engenharia de

Produção com ênfase em

Gerência de Produção,

possui graduação em

Ciências Contábeis,

especialização em Auditoria

Contábil e Controladoria

da Gestão Empresarial e

atualmente é Contador

da Unidade Estadual

do IBGE no Amazonas

e Professor Adjunto III

do Departamento de

Contabilidade da Faculdade

de Estudos Sociais (FES)

da Universidade Federal

do Amazonas (UFAM).
RESUMO: A qualidade na educação é de extrema importância para que ocorra um desenvolvimento na sociedade. Desta maneira, o presente artigo teve como objetivo analisar as receitas arrecadadas e despesas empenhadas extraídas dos relatórios de gestão da Universidade Federal do Amazonas, nos períodos de 2015 a 2017. Foi utilizada a metodologia da pesquisa descritiva, quantitativa, bibliográfica e documental utilizando a estatística descritiva. Do resultado, concluiu-se que o coeficiente de correlação ( $\mathrm{r}$ de Pearson) foi de 0,93 demonstrando uma correlação muito alta entre as receitas arrecadadas as despesas empenhadas, constatando-se que à medida que as receitas arrecadadas aumentavam, houveram aumento ainda maior nas despesas empenhadas, demonstrando um déficit na execução orçamentária. As receitas demonstraram também um coeficiente de variação de 52,90\%, enquanto as despesas mostraram uma variação de 6,14 \%, demonstrando uma dispersão entre os valores da média da série, a variação do desvio padrão com relação à média informa que: subtraindo-se da média verificou o resultado de $\mathrm{R} \$ 6.040 .034,90$, enquanto que se adicionando a média resultou em $R \$ 19.606 .145,10$ de variações de recursos. Esta pesquisa analisou as receitas ordinárias e vinculadas e despesas ordinárias e vinculadas orçamentariamente pelos seus totais dos períodos analisados nesta pesquisa.

palavras-chave: Relatório de Gestão; Receitas Públicas; Despesas Públicas;

ABSTRACT: Quality in education is of utmost importance for development in society. Thus, this article aimed to analyze the collected revenues and committed expenses extracted from the management reports of the Federal University of Amazonas, from 2015 to 2017. We used the descriptive, quantitative, bibliographic and documentary research methodology using statistics. Descriptive. From the result, it was concluded that the correlation coefficient (Pearson's r) was 0.93 demonstrating a very high correlation between revenue collected and committed expenditure, and it was found that as the revenue collected increased, there was an even greater increase. Expenditure committed, demonstrating a deficit in budget execution. Revenues also showed a coefficient of variation of $52.90 \%$, while expenses showed a variation of $6.14 \%$, showing a dispersion between the series average values, the variation of the standard deviation in relation to the average states that: subtracting The average result was $R \$ 6,040,034.90$, while adding the average resulted in R \$ 19,606,145.10 of changes in resources. This survey analyzed ordinary and linked revenues and ordinary and budgeted expenses by their totals for the periods analyzed in this survey.

KEYwORDs: Management Report; Public Revenues; Public Spending; 


\section{INTRODUÇÃO}

Atualmente existem várias discussões sobre forma de estruturação das Instituições Federais de Ensino Superior, com objetivo de melhorar a economia e os gastos públicos. O tema desta pesquisa está relacionado à uma análise das receitas arrecadadas e despesas empenhadas no período de 2015 a 2017 da Universidade Federal do Amazonas na função educação de ensino superior extraídas do Plano de Desenvolvimento Institucional (PDI) e de seus relatórios de gestão.

Analisando como estão distribuídas as despesas e receitas na execução orçamentária das atividades de ensino superior exposta nos relatórios de gestão da instituição no qual deve evidenciar seu posicionamento a respeito da gestão da universidade no âmbito social, educacional e de garantir o cumprimento de suas políticas e ações. O posicionamento perante a esses quesitos citados estão em conformidade com Plano de Desenvolvimento Institucional (PDI) que é muito mais que documento técnico-burocrático, deve ser considerado instrumento de execução administrativa e pedagógica que garante um norteamento na gestão da universidade, por meio de processos a serem desenvolvidos no decorrer dos anos pela administração da instituição, e que serve para tornar essa administração capaz para a formação profissional, o exercício da cidadania e o pleno desenvolvimento.

Segundo Abrahão (2005, p. 842) a educação, ao situar-se no âmbito das responsabilidades do Poder Público, compondo o núcleo central dos atuais sistemas de bem-estar social, absorve quantidade expressiva de recursos públicos. Para que ocorra benfeitorias na sociedade, há uma necessidade de que haja um investimento expressivo na educação, pois ela é um dos pilares para contribuição de melhoria social.

Medeiros (2013, p. 131) descreve que uma educação de qualidade proporciona ao indivíduo oportunidades melhores no mercado de trabalho, com benefícios e remuneração adequados o que, por sua vez, aumenta a inclusão social e fortalecimento da democracia a partir do momento em que ele se sente parte dessa sociedade e se torna ativo e consciente dos seus direitos e deveres como cidadão.

Conforme Magro e Rausch (2012, p. 428) a qualidade no ensino está diretamente relacionada ao modelo de gestão utilizados pelas universidades. Uma excelente gestão da administração terá com retorno um ensino de excelente qualidade também.

Contudo é necessário um planejamento de qualidade para que tais objetivos no âmbito da educação pública sejam atendidos. Por conta da necessidade de um planejamento adequado as universidades estão investindo em um Plano de Desenvolvimento Institucional. Para Otani (2011, p. 2) o Plano de Desenvolvimento Institucional que convergiu esforços para inserir as instituições em um contexto de expansão orientada, consolidando políticas e ações dentro de um escopo hermético, direcionado a atender aos pressupostos regulatórios e de avaliação". 
Picawy (2007, p. 79) relata que "[...] através da elaboração e publicação de documentos norteadores, orientadores e disciplinadores. As instituições de Ensino Superior se organizam numa concepção nacional de princípios, competências e diretrizes a graduação e pós-graduação". O PDI passa a ser considerado um documento estruturante do processo de planejamento institucional, desencadeando oportunidades de estudos sistemáticos no sentido de promover uma compreensão do escopo institucional a partir de ações concretas. (FRANCISCO, 2012, p. 84)

Em relação aos gastos com a educação a administração das universidades públicas devem apenas fazer despesas que tragam benefícios para as universidades, com intenção de atingir a qualidade da educação e deixando claro que todos os recursos investidos nelas estão sendo utilizados de forma eficiente e que beneficie a sociedade como um todo.

[...] a administração pública deve efetuar despesas que promovam a eficiência na prestação dos serviços objetivando alcançar a eficácia nos sistemas de ensino, a fim de atingir níveis aceitáveis de desempenho, de forma a refletir no melhor desenvolvimento acadêmico da instituição (COSTA, 2011, p. 1).

O objetivo principal neste estudo foi de analisar a execução orçamentária da instituição federal de ensino superior em relação aos seus gastos com a educação extraídos dos relatórios de gestão nos períodos de 2015 a 2017. De forma mais sucinta, analisou-se a execução orçamentária da instituição federal de ensino superior extraídos dos relatórios de gestão do período em análise, identificou-se os valores das receitas arrecadadas e das despesas empenhadas no orçamento da instituição federal de ensino superior extraídos dos relatórios de gestão no período analisado e avaliou-se os resultados entre receitas e despesas públicas da execução orçamentária da instituição de ensino superior nos períodos de 2015 a 2017.

A pesquisa justifica-se, a necessidade da sociedade pela cobrança em relação a transparência dos gastos públicos, ela vem cada vez mais exigindo que haja uma comprovação de que realmente seus governantes estão investindo com uma melhor gestão os recursos públicos disponíveis, isso em todos os âmbitos sociais, como saúde, cultura, infraestrutura etc.

Sendo assim, o problema da pesquisa é: Os recursos públicos destinados à educação de ensino superior têm sido aplicados de modo eficiente pela Universidade Federal do Amazonas no período em análise? Verifica-se que cada vez mais a sociedade vem exigindo uma maior transparência e eficiência em toda gestão do setor público, e que não há diferença em relação as instituições públicas de ensino superior. Há a necessidade que se tenha uma comprovação de melhorias na gestão de seus gastos públicos. 
O artigo foi formado por quatro tópicos, além desta introdução. $\mathrm{O}$ segundo composto pela fundamentação teórica. $\mathrm{O}$ terceiro com o procedimento da pesquisa, seguido da análise dos resultados e por fim, as considerações finais, recomendação e conclusão.

Com o intuito de atingir os objetivos propostos neste trabalho, os processos metodológicos utilizados na confecção desta pesquisa foram fundamentados em pesquisas, quantitativas, bibliográficas, documental e o uso da estatística descritiva.

A pesquisa possui uma abordagem descritiva, que segundo Gil (2002, p. 42) as pesquisas descritivas têm como objetivo primordial a descrição das características de determinada população ou fenômeno ou, então, o estabelecimento de relações entre variáveis. No presente estudo serão examinados os gastos com a educação de ensino superior na Universidade Federal do Amazonas nos anos de 2015 a 2017, para que se façam comparações com as teorias e análise de informações já existentes tornando a metodologia desta pesquisa mais compreensível.

O estudo abrange a natureza da pesquisa quantitativa, que para Rampazzo (2002, p. 58) a pesquisa quantitativa se inicia com o estudo de um certo número de casos individuais, quantifica fatores segundo um estudo típico, servindo-se frequentemente de dados estatísticos, e generaliza o que foi encontrado nos casos particulares. Por meio da verificação das receitas arrecadadas e despesas empenhadas extraídas dos balanços orçamentários dos anos de 2015 a 2017, da Universidade Federal do Amazonas, onde os dados foram identificados através dos Relatórios de Gestão da universidade.

O meio de investigação requer um estudo bibliográfico, que conforme Macedo (1994, p. 13) é a busca de informações bibliográficas, seleção de documentos que se relacionam com o problema da pesquisa (livros, verbetes de enciclopédia, artigos de revistas, trabalhos de congressos, teses e etc.). Permitindo a compreensão das ideias principais dos autores, mediante artigos científicos e livros já publicados, tornando possível um vasto conhecimento e também fornecendo informações sobre a problemática da pesquisa.

A pesquisa documental, que segundo Rampazzo (2002, p. 51) é chamada de documental porque procura os documentos de fonte primária, a saber, os dados primários provenientes de órgãos que realizaram as observações. Esses dados primários podem ser encontrados em arquivos, fontes estatísticas e fontes não-escritas. É uma análise em documentos ou materiais legítimos, que serão comparados com a realidade do gasto com a da educação de ensino superior, com o objetivo de obter e assimilar a partir da análise das despesas públicas dos balanços orçamentários o grau de eficiência dos recursos públicos.

No que se refere a análise dos dados, esta pesquisa tratará a estatística descritiva, que conforme Correa (2003, p. 9) é o conjunto de técnicas que objetivam coletar, organizar, apresentar, analisar e sintetizar os dados numéricos de uma população, ou amostra. (CORREA, 2003, p. 9). 
Serão utilizados os métodos estatísticos, segundo Stevenson (2001, p. 11):

Os métodos estatísticos envolvem a análise e a interpretação de números, tais como renda anual, vendas mensais, escores de testes, número de peças defeituosas, percentagem de respostas favoráveis a um questionário, vida ativa, etc. Tais números são designados por dados. Para interpretar os dados corretamente, em geral é preciso primeiro organizar e sumarizar os números.

Será feita uma verificação das informações através de uma análise, na qual serão aplicados os métodos estatísticos tais como: a média aritmética, o desvio padrão, o coeficiente de variação, a variância e os números índices.

\section{FUNDAMENTAÇÃO TEÓRICA}

\section{INSTITUIÇÕES DE ENSINO SUPERIOR}

As Instituições de Ensino Superior são instituições que proporcionam educação a nível superior, pode ser formada por faculdades, escolas ou institutos que oferecem aprendizagem a este nível, são institutos profissionalizantes que capacitam o estudante ao mercado de trabalho.

A universidade é considerada uma das mais complexas organizações de nossa sociedade. Criada no século XII, constitui-se numas das mais importantes organizações sociais tendo, ao longo de sua existência, enfrentando as mais diversas crises. Essas crises têm sua origem em fatores internos como também fatores externos (JÚNIOR, 2005, p. 374)

Magro e Rausch (2012, p. 430) destacam que as instituições de ensino superior são organizações complexas, que se caracterizam pela existência de vários processos produtivos, sendo eles: ensino, pesquisa e extensão. As instituições de ensino superior investem em ensino, pesquisa e extensão para que a qualidade na aprendizagem seja mais eficiente, esse investimento em pesquisas trazem um retorno satisfatório para a sociedade.

A universidade é uma instituição complexa em várias dimensões: na variedade e quantidade de públicos (ou stakeholders) com os quais se relaciona; na multiplicidade de objetivos; na diversidade de serviços oferecem; na diversidade de formação de seus recursos humanos; nos diversos tipos de tecnologias que deve dominar; e, geralmente, na extensão da infraestrutura que possui. Quando a universidade é uma instituição pública, soma-se a estas características outros elementos peculiares do setor público, entre eles, a profusão de normas emanadas dos poderes centrais, as pressões políticas, a escassez de recursos e a lentidão do processo decisório burocrático. (SANTOS 2009, p. 2). 
Conforme Costa (2011, p. 6) atualmente, são as universidades públicas que oferecem os melhores cursos de graduação e pós-graduação e, em seu interior, é realizada a maior parte da produção científica, tecnológica e cultura.

\section{ORÇAMENTO PÚBLICO}

Conforme Medeiros (2013, p.132 apud Giacomoni, 2003), o orçamento público é caracterizado por possuir uma multiplicidade de aspectos: políticos, jurídicos, contábil, econômico, financeiro, administrativo entre outros.

[...] é um mecanismo utilizado pelos órgãos públicos como uma forma de planejamento e melhor utilização dos recursos fazendo uma estimativa de receitas arrecadada e a fixação de despesas movimentando a máquina pública. Apresenta múltiplas funções de planejamento, contábil, financeira e de controle. (PAZ; ALMEIDA E SILVA, 2012, p. 37)

O orçamento público é uma espécie de lei que representa em financeiros a destinação dos recursos públicos. Refere-se a uma ferramenta de planejamento que expressa as medidas políticas, determinando as ações prioritárias para o auxílio das necessidades da sociedade, em relação da escassez de recursos.

\section{GASTOS PÚBLICOS COM EDUCAÇÃO}

A educação, na perspectiva de direito social, concorre com as demais áreas pela canalização de recursos. (CONCEIÇÃO, 2016)

As normas de contabilidade aplicadas ao setor público estão dentro dos padrões da contabilidade brasileira e internacional, e tudo isso se deve ao fato de que as informações necessitam ter clareza e transparência em seus dados para que assim haja uma fácil compreensão. (BERLT, 2017, p. 88)

Todo e qualquer recurso público investido em educação deve ter transparência, ou seja, deve ser nítido o gasto feito pela instituição para melhoria da universidade, contudo esse gasto deve ser explicito nos relatórios de gestão da mesma, mostrando sua eficácia.

Conforme Abrahão (2005, p. 850):

[...] a atual Constituição Federal brasileira atribui aos estados e munícipios a responsabilidade pela oferta da educação básica, cabendo ao governo federal apenas a função supletiva; assim, a maior parte dos recursos aplicados pelo governo federal, na área da educação, destina-se ao custeio das instituições federais de ensino superior (IFES), escolas técnicas federais e centros federais de ensino tecnológico (CEFET).

O Governo Federal é quem é responsável pela destinação dos recursos para investimento em educação a nível superior. 


\section{O FINANCIAMENTO DO GASTO PÚBLICO COM EDUCAÇÃO}

Os entes federativos são responsáveis por manter e expandir os três sistemas de ensino que são: ensino fundamental, médio e superior. E para realizar os gastos com esses sistemas, cada ente se responsabiliza por um sistema específico. O Governo Municipal pelo ensino fundamental, o Governo Estadual pelo ensino médio e o Governo Federal pelo ensino superior.

Segundo Abrahão (2005, p.842):

A educação pública, de acordo com as normas legais vigentes, deve ser realizada pela União, pelos estados, pelo Distrito Federal e pelos munícipios, que têm a responsabilidade e competência pela manutenção e expansão de três sistemas de ensino. Para viabilizar os gastos com esses sistemas, foi estabelecida uma estrutura de financiamento correspondente.

O ente federativo responsável de forma supletiva pelo financiamento na função educação é a União, ela financia os recursos aos demais entes federativos e tem como objetivo garantir que os recursos destinados à educação sejam a um patamar mínimo.

Conforme Conceição (2016, p. 36) apud Melchior (1987):

A origem dos recursos que subsidiam a educação no país tem forte vínculo com o pacto federativo, ou seja, com o poder constitucional de tributar dos entes federativos (União, Estados e Municípios), a vinculação ou não vinculação dos recursos arrecadados por meio de sua receita tributária, o direito residual da União em legislar em matéria tributária e da sua responsabilidade supletiva no financiamento da educação aos demais entes federativos de forma a garantir um patamar mínimo de recursos destinados ao financiamento da educação.

Abrahão (2005, p.843) ressalta ainda que:

A União deve aplicar recursos na execução de alguns programas/ações próprios, além de poder transferir recursos para os sistemas estaduais e municipais. Na composição de suas receitas, os estados somam os recursos recebidos da União aos provenientes de suas fontes, os quais são utilizados na manutenção e expansão de seus sistemas de ensino. A estrutura de financiamento da educação é fortemente baseada em impostos, que são recursos gerais tomados da sociedade.

A fonte de recurso arrecado para investimento em educação em sua maioria é vinda de impostos, uma pequena parte é vinda das contribuiç̧ões sociais, outra parte vem de operações de créditos internacionais e de aplicações financeiras, ou até mesmo de recurso arrecadados pelas próprias instituições (CASTRO 2001 p.13). 
Para CASTRO (2001 p.13) a maior parte dos recursos sendo proveniente de fontes do aparato fiscal, que é o caso típico dos recursos da vinculação de impostos. Parcela razoável provém das contribuições sociais, principalmente das contribuições originalmente destinadas ao financiamento da seguridade social e daquela contribuição criada exclusivamente para a educação que é o salário-educação. Outra parte provém de operações de crédito com agências internacionais e, por último, tem-se as outras fontes em que entram desde as aplicações financeiras do Fundo Nacional de Desenvolvimento da Educação (FNDE) até os recursos arrecadados diretamente pelas instituições vinculadas. A partir de 1994, um fundo de financiamento atípico, o Fundo Social de Emergência (FSE) começou a funcionar e, também, foi utilizado para financiar a educação.

\section{PROCEDIMENTOS DA PESQUISA}

\section{MÉDIA ARITMÉTICA}

A média, assim como a mediana e a moda são medidas de tendência central, ou seja, são usadas para indicar um valor que tende a tipificar, ou a representar melhor, um conjunto de números. (STEVENSON, 1981, p. 19)

A média aritmética é um ponto entre os extremos, ou seja, não pode ser menor que o menor dos valores da série nem tampouco maior que o maior destes valores. É uma medida tão mais representativa de uma série estatística, quanto mais concentrada estiverem os valores desta série estatística, quanto mais concentrados estiverem os valores desta série em torno do seu valor. É utilizada para cálculo de dispersão, bem como na comparação com outras medidas de tendências centrais (Oliveira, 2010, p.96).

$$
\text { Média }=\frac{\sum_{i=1}^{n} X_{i}}{n}
$$

$$
\text { Média }=\frac{\mathrm{x}_{1}+\mathrm{x}_{2}+\mathrm{x}_{3}+\ldots \mathrm{x}_{\mathrm{n}}}{\mathrm{n}}
$$

DESVIO - PADRÃO

O desvio-padrão é a medida mais usada na comparação de diferenças entre conjuntos de dados, por ter grande precisão. O desvio padrão determina a dispersão dos valores em relação à média e é calculado por meio da raiz quadrada da variância (CORREA 2003, p. 61).

O desvio padrão é uma das medidas mais comumente usadas para distribuições, e desempenha papel relevante em toda a estatística. Cabe notar que a unidade do desvio padrão é a mesma da média. Por exemplo, se a média é em cruzeiros, o desvio padrão também se 
exprime em cruzeiros. A variância, por outro lado, se exprime em quadrados de unidades (STEVENSON, 2001, p. 19).

$$
\text { Desvio-Padrão }=\sqrt{\frac{\sum(x-\text { Média })^{2}}{n-1}}
$$

\section{VARIÂNCIA}

Correa (2003, p. 60) "a variância leva em consideração os valores extremos e os valores intermediários, isto é, expressa melhor os resultados obtidos. A variância relaciona os desvios em torno da média, ou, mais especificamente, é a média aritmética dos quadrados dos desvios".

Sendo a variância calculada a partir dos quadrados dos desvios, ela é um número em unidade quadrada em relação à variável em questão, o que, sob o ponto de vista prático, é um inconveniente; por isso, tem pouca utilidade na estatística descritiva, mas é extremamente importante na inferência estatística e em combinações de amostras (CORREA 2003, p. 60).

$$
\text { Variancia }=\frac{\sum(X-\text { Média })^{2}}{n-1}
$$

\section{COEFICIENTE DE VARIAÇÃO}

Trata-se de uma medida relativa de dispersão útil para a comparação em termos relativos do grau de concentração. O coeficiente de variação é a relação entre o desvio padrão $(S)$ e a média x (CORREA 2003, p. 61).

Para Reis (2008, p. 114) quanto menor o coeficiente de variação percentual, mais os dados estão concentrados em torno da média, pois o desvio padrão é pequeno em relação à média.

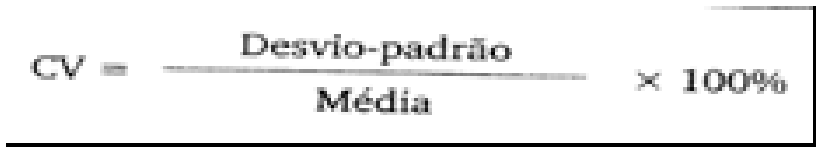

\section{NÚMEROS ÍNDICES}

Números índices são processos estatísticos baseados na razão matemática, objetivando medir ou comparar situações em períodos diferentes de tempo, quando as grandezas estão relacionadas entre si. O uso dos números - índices se têm limitado, na prática, ao campo econômico e ao mundo dos negócios, onde tem largo emprego. Contudo, a sua aplicabilidade parece ter-se generalizado o bastante para serem empregados amplamente em outros setores, com vantagem (Oliveira,2010, p. 479). 


\section{RESULTADOS E ANÁLISE DOS DADOS}

Neste tópico, demonstrou os resultados obtidos por meio da análise descritiva de cada indicador, no qual os resultados foram demonstrados através da pesquisa extraída dos Balanços Orçamentários, através dos Relatórios de Gestão da UFAM, demonstrado o crescimento do gasto público em educação superior. Deste modo, os dados obtidos foram analisados com base na comparação e evolução dos dados no período compreendendo os anos de 2015 a 2017.

QUADRO 01 - Variação entre Receitas e Despesas.

\begin{tabular}{|l|c|c|c|c|c|c|c|}
\hline & 2015 & 2016 & 2017 & Média & S & CV \\
\hline Receitas Arrecadadas & $8.818 .628,38$ & $8.995 .822,39$ & $20.654 .819,23$ & $12.823 .090,00$ & $6.783 .055,10$ & 46.009 .836 .478 .32220 & $52,90 \%$ \\
\hline Despesas Empenhadas & $699.519 .002,56$ & $750.056 .136,38$ & $791.143 .864,33$ & $746.906 .334,42$ & $45.893 .569,95$ & $2.106 .219 .762 .867 . .570,00$ & $6,14 \%$ \\
\hline Déficit & $-690.700 .374,18$ & $-741.060 .313,99$ & $-770.489 .045,10$ & $-734.083 .244,42$ & $40.349 .320,03$ & $1.628 .067 .626 .598 .600,00$ & $-5,50 \%$ \\
\hline
\end{tabular}

FONTE: Dados extraídos dos Relatórios de Gestão 2015, 2016, 2017.

GRÁFICO 01 - Variação entre Receitas e Despesas.

\section{Variação entre Receitas e Depesas}

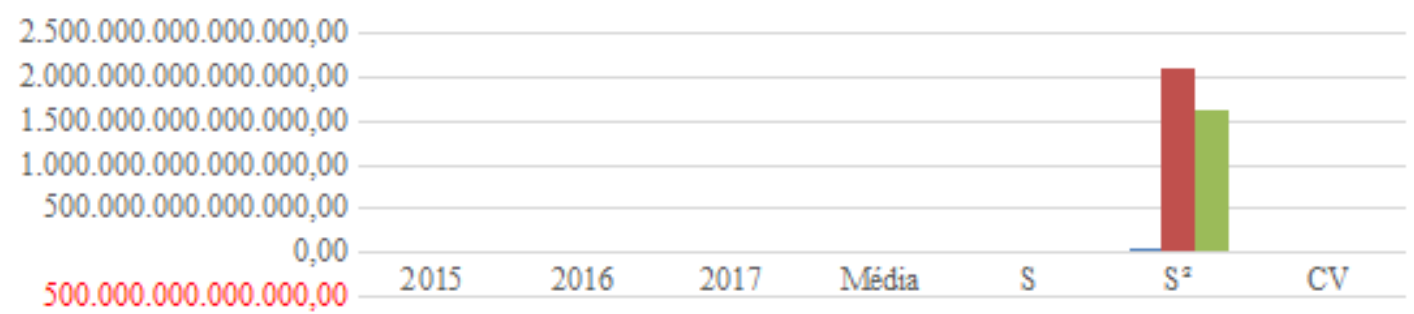

- Receitas Arrecadadas n Despesas Empenhadas n Déficit

GRÁfiCO 01 - Elaborado pela autora- FONTE: Dados extraídos dos Relatórios de Gestão da UFAM 2015, $2016,2017$.

Observa-se que se comparados os valores das médias anuais, através do cálculo média aritmética, do período em análise, a UFAM está com um valor muito distante entre suas Receitas e Despesas. Nas Receitas Arrecadadas a média anual foi de R\$ 12 milhões enquanto a média anual das Despesas Empenhadas foi de R 746 milhões. Dessa forma, verificou-se que houve variações entre os valores das Receitas e Despesas pelo motivo da Instituição pesquisada não ter tido 
arrecadação suficiente para cobrir o montante das suas despesas.

De acordo com Silva (2012, p.7), descreve que o cálculo do desvio-padrão tem como finalidade medir a dispersão média entre duas variáveis, dessa maneira, as Receitas Arrecadadas devem demonstrar o menor desvio-padrão (mais regularidade) ou a maior (menos regularidade) dispersão dos dados em relação à media, demonstrando neste resultado o valor de $\mathrm{R} \$ 6.783 .055,10$, considerado que apresentou a menor dispersão em relação as Despesas Executadas que apresentaram $\mathrm{R}$ \$ 45.893.569,95, a maior dispersão analisada. Os valores da variância retratam se a média dos quadrados dos desvios são iguais. Nesta análise, as Receitas Arrecadadas tiveram mais regularidade, isto quer dizer que em relação às suas médias houve menos dispersão.

Silva (2012, p.12) descreve a seguinte interpretação do coeficiente de variação:

I) $\mathrm{CV} \leq 15 \%$ há uma baixa dispersão dos valores em torno da média e grande representatividade da média da série;

II) $15 \%<\mathrm{CV}<30 \%$ Média dispersão dos valores em torno da média e média representatividade da média da série.

III) $\mathrm{CV} \geq 30 \%$ Alta dispersão dos valores em torno das médias e baixa representatividade da média da série.

Em relação ao cálculo do Coeficiente de Variação observou-se que o CV das receitas e despesas foram, respectivamente, 52,90\% e 6,14\%. $\mathrm{O} C V$ das Receitas Arrecadadas evidenciou uma alta dispersão dos valores e baixa representatividade da média da série ( $C V \geq 30 \%)$, ou seja, ao analisar as Receitas, foi possível verificar que a UFAM possui uma média de $\mathrm{R} \$ 12$ milhões, com uma variação dos recursos de $\mathrm{R} \$ 6$ a 18 milhões (desvio-padrão de $\mathrm{R} \$ 6$ milhões), já na aplicação dos recursos, ou seja, as Despesas Empenhadas, observou-se que a UFAM demonstrou uma baixa dispersão dos valores em torno da média e grande representatividade da média da série, verificando-se uma média de $\mathrm{R} \$ 746$ milhões, com uma variação de aplicação de recursos de $\mathrm{R}$ \$ 701 milhões a R \$ 791 milhões (desvio-padrão de R 45 milhões) .

Cálculo do nível de correlação real entre as receitas arrecadadas na função Educação Superior, e as despesas empenhadas. Demonstração do cálculo do coeficiente de correlação e de determinação de Pearson (r e r2).

De acordo com Silva (2012, p.15) o coeficiente de correlação pode ser interpretado da seguinte maneira: 
QUADRO 02 Interpretação do Coeficiente de Correlação

\begin{tabular}{|c|c|}
\hline COEFICIENTE & INTERPRETAÇÃO \\
\hline $\mathrm{r}=1$ & CORRELAÇÃO PERFEITA \\
\hline $0,80<\mathrm{r}<1$ & MUITO ALTA \\
\hline $0,60<\mathrm{r} 0,80$ & ALTA \\
\hline $0,40<\mathrm{r} 0,600$ & MODERADA \\
\hline $0,20<\mathrm{r}<0,40$ & BAIXA \\
\hline $0<\mathrm{r}<0,20$ & MUITO BAIXA \\
\hline $\mathrm{R}=0$ & NULA \\
\hline
\end{tabular}

FONTE: Silva (2012, p. 15).

\begin{tabular}{|c|c|c|c|c|c|c|}
\hline & \multicolumn{7}{|c|}{ TABELA 2 - COEFICIENTE DE CORRELAÇÃO } \\
\hline & Despesas(X) & Receitas(Y) & $\mathbf{X Y}$ & $\mathbf{X}^{\mathbf{2}}$ & $\mathbf{Y}^{\mathbf{2}}$ \\
\hline $\mathbf{2 0 1 5}$ & $699.519 .002,56$ & $8.818 .628,38$ & $6.168 .798 .128 .324 .910,00$ & $489.326 .834 .942 .537 .000,00$ & $77.768 .206 .504 .541,40$ \\
\hline $\mathbf{2 0 1 6}$ & $750.056 .136,38$ & $8.995 .822,39$ & $6.747 .371 .785 .404 .100,00$ & $562.584 .207 .721 .293 .000,00$ & $80.924 .820 .472 .425,30$ \\
$\mathbf{2 0 1 7}$ & $791.143 .864,33$ & $20.654 .819,23$ & $16.340 .933 .502 .659 .800,00$ & $625.908 .614 .067 .006 .000,00$ & $426.621 .557 .423 .978,00$ \\
\hline Total & $2.240 .719 .003,27$ & $38.469 .270,00$ & $29.257 .103 .416 .388 .800,00$ & $1.677 .819 .656 .730 .840 .000,00$ & $585.314 .584 .400 .944,00$ \\
\hline Média & $746.906 .334,42$ & $12.823 .090,00$ & $9.752 .367 .805 .462 .930,00$ & $559.273 .218 .910 .279 .000,00$ & $195.104 .861 .466 .981,00$ \\
\hline
\end{tabular}

\section{Coeficiente de Correlação R= 0,93}

Através do cálculo verificou-se que o coeficiente de correlação ( $\mathrm{r}$ de Pearson) foi de o,93 que por meio dos resultados obtidos tornou-se possível a compreensão de que existe uma correlação muito alta entre as receitas arrecadadas na função educação de ensino superior e suas despesas empenhadas, constatando-se que à medida que as receitas arrecadadas aumentaram, no entanto, houve um aumento das despesas empenhada da função educação de ensino superior, ou seja, verificou-se que à medida em que havia aumento das receitas haviam também aumento das despesas, e quanto mais arrecadavam mais executavam gastos com as despesas.

Verificou-se que as receitas demonstraram um coeficiente de variação de 52,90\%, enquanto as despesas mostraram uma variação de 6,14 \%, demonstrando uma dispersão entre os valores da média da série, a variação do desvio padrão com relação à média informa que: subtraindo-se da média verificou o resultado de $R \$$ 6.040.034,90, enquanto que se adicionando a média resultou em $\mathrm{R}$ \$ 19.606.145,10 de variações de recursos.

Assim como, nas receitas arrecadadas encontra-se uma variação $134,22 \%$ (variou de $R \$ 8.818 .628,38$ para $\mathrm{R} \$$ 20.654.991,39) e as despesas empenhadas de 13,10\% (variou de $R \$ 699.519 .002,56$ para $R \$ 791.155 .991,90$ ), ou seja, as receitas 
arrecadadas apontaram uma boa variação das receitas, porém os valores das Despesas Empenhadas foram muito maiores se comparados seus montantes. Verificou-se que nos três anos demonstraram déficit na execução orçamentária e seguidamente.

\begin{tabular}{|c|c|c|}
\hline RECEITA & & \\
\hline EXECUTADA & & \\
\hline $20158.818 .628,38$ & \multirow{2}{*}{ ANO BASE } & \\
\hline $201720.654 .819,23$ & & \\
\hline \multicolumn{3}{|c|}{$X=20.654 .819,23 \times 100 / 8.818 .628,38=234.22-100=134,22 \%$} \\
\hline \multicolumn{3}{|l|}{ DESPESA } \\
\hline \multicolumn{3}{|l|}{ EXECUTADA } \\
\hline $2015699.519 .002,56$ & \multirow{2}{*}{ ANO BASE } & \\
\hline $2017791.143 .864,33$ & & \\
\hline \multicolumn{3}{|c|}{$X=791.143 .864,33 \times 100 / 699.519 .002,56=113.10-100=13,10 \%$} \\
\hline
\end{tabular}

\section{CONCLUSÕES E RECOMENDAÇÕES}

Com foco nos objetivos propostos, o presente estudo demonstrou a análise das receitas arrecadadas e das despesas empenhadas em educação de ensino superior, através dos Balanços Orçamentários dos anos de 2015 a 2017, publicados nos Relatórios de Gestão da Universidade Federal do Amazonas, que são auditados pelo Tribunal de Contas da União (TCU). Para a análise da pesquisa foram utilizados os métodos estatísticos para demonstrar o desempenho das receitas arrecadadas e das despesas empenhadas por meio de indicadores, gráficos e tabelas, os dados foram extraídos do Relatório de Gestão consolidados de 20092017 e analisou-se as receitas ordinárias e vinculadas bem como as despesas ordinárias e vinculadas orçamentariamente na sua execução, pelos seus totais dos períodos analisados nesta pesquisa.

A área da educação pública se tornou ao longo dos anos uma das prioridades do governo, tornando-se um dos seus principais investimentos, onde grande parte dos recursos públicos é destinado para que haja um crescimento na demanda de beneficiados, e que tenha como resultado um retorno para a sociedade, com o aumento do conhecimento, refletindo no desenvolvimento do país.

Porém, é de extrema importância que haja uma limitação dos recursos públicos, para a obtenção de uma maior e melhor aplicação dos mesmos. Nesse sentido, em resposta à questão do problema, ao perguntar se os recursos públicos destinados à educação de ensino superior têm sido aplicados de modo eficiente pela Universidade Federal do Amazonas no período em análise, e respondendo esta questão do problema, analisou-se que os dados das receitas arrecadadas e despesas empenhadas da UFAM no período de 2015 a 2017demonstraram um valor de $\mathrm{R} \$$ 746.906.334,42 na média anual das despesas empenhas em educação superior para os anos analisado, enquanto a média das receitas arrecadadas foi encontrado um valor de $\mathrm{R} \$$ 12.823.090,00, a média anual das receitas corresponde há $1,72 \%$ da média de gasto analisado, 
apresentando assim déficit na execução orçamentária.

Verificou-se também, um resultado deficitário, apesar da variação da receita arrecadada ter sido de $134,22 \%$ (variou de R $\$ 8.818 .628,38$ para $\mathrm{R} \$ 20.654 .991,39$ ) e as despesas empenhadas de $13,10 \%$ (variou de $\mathrm{R} \$$ 699.519.002,56 para $\mathrm{R} \$$ 791.155.991,90), no entanto, como citado anteriormente ao analisar os dados como um todo, verificou-se que as despesas empenhadas foram muito maiores do que as receitas arrecadadas, ocorrendo um déficit na execução orçamentária em análise das informações serviu para apuração dos resultados das receitas arrecadadas e despesas empenhadas na universidade em estudo, e por meio disso gerar informações para que os usuários possam saber sobre a gestão dos recursos da universidade.

Deste modo, como o objetivo da pesquisa foi de analisar a execução das receitas e despesas da universidade, mostrou uma situação financeira não favorável devido ao déficit no período analisado. Como recomendação é de extrema importância um acompanhamento periódico dos exercícios financeiros, para que seja possível fazer uma comparação de como está a situação econômica e financeira da universidade, analisando os gastos e os investimentos na educação, tornando mais eficiente a gestão da universidade.

\section{REFERÊNCIAS}

ABRAHÃO, Jorge. Financiamento e Gasto Público da Educação Básica no Brasil e Comparações com alguns Países da OCDE e América Latina. Educação \& Sociedade, Campinas, v. 26, n. 92, p. 841-858, 2005. ISSN: 0101-7330. Disponível em: http://www.scielo.br/pdf/es/ v26n92/v26n92ao7.pdf. Acesso em: 23 nov. 2017. às 15:02.

BERLT, C. R. et al. Gastos Públicos: Análise da Aplicação da Lei de Responsabilidade Fiscal e da Constituição Federal no COREDE Alto Jacuí. Rev. Adm. UFSM, Santa Maria, v. 10, número 1, p. 85-100, JAN. - MAR. 2017. Disponível em: http://www.redalyc.org/ pdf/2734/273450498006.pdf. Acesso em: 23 nov. 2017. às 15:05.

CASTRO, Jorge Abrahão de. Financiamento da Educação no Brasil. Em Aberto, Brasília, v. 18, n. 74, p. 11-32, dez. 2001. Disponível em: http://www. emaberto.inep.gov.br/index.php/emaberto/article/ download/2150/2119. Acesso em: 23 nov. 2017. às 22:17.

CONCEIÇÃO, Sérgio Henrique da. Perspectivas e Desafios do Plano Nacional de Educação (PNE) (2014-2024) no Contexto do Financiamento da Educação Básica. Educação em Revista, Marília, v. 17, n. 1, p. 35-54, Jan.-Jun., 2016. Disponível em: http:// www2.marilia.unesp.br/revistas/index.php/educacaoemrevista/ 
article/view/5862/3989. Acesso em: 26 nov. 2017. às 19:58.

CORREA, Sonia Maria Barros Barbosa. Probabilidade e estatística. PUC Minas Virtual, Belo Horizonte, 2. ed., 2003. Disponível em: http://estpoli.pbworks. com/f/livro_probabilidade_estatistica_2a_ ed.pdf. Acesso em: 10 jun. 2018 às 17:00

COSTA, C. C. M. et al. A Execução Orçamentária da Universidade Federal De Sergipe: Uma breve análise do período 2007 a 2010. XI Colóquio Internacional sobre Gestão Universitária na América do Sul, Florianópolis, 2011. Disponível em: https://repositorio.ufsc.br/xmlui/ handle/123456789/26095. Acesso em: 20 nov. 2017. às 20:19.

FRANCISCO, T. H. A. et al. A Contribuição do PDI nas atividades de Planejamento e Gestão das Instituições de Educação Superior. Revista GUAL, Florianópolis, v. 5, n. 3, p. 81-107, 2012. Disponível em: https:// periodicos.ufsc.br/index.php/gual/article/viewFile/19834535.2012v5n3p81/23666. Acesso em: 23 nov. 2017. às 21:48.

\section{GIL, Antônio Carlos. Como elaborar projetos} de pesquisa. 4. ed. São Paulo: Atlas, 2002.

JÚNIOR, Victor Meyer. Planejamento Universitário: Ato racional, político ou simbólico - um estudo de universidades brasileiras. Alcance: UNIVALI, v. 12, n. 3, p. 373-389, 2005. Disponível em: http://www.redalyc.org/ html/4777/477748620006/. Acesso em: 23 nov. 2017. às 21:51.

MACEDO, Neusa Dias de. Iniciação à pesquisa bibliográfica: guia do estudante para a fundamentação do trabalho de pesquisa. Edições Loyola, São Paulo, 2. ed., 1994. Disponível em: https://books.google.com.br/books?hl=pt-BR\&lr=\&id=2zoA3cc6o UEC\&oi=fnd\&pg=PA7\&dq $=$ Inicia $\% \mathrm{C}_{3} \% \mathrm{~A}_{7} \% \mathrm{C}_{3} \% \mathrm{~A}_{3} \mathrm{O}+\% \mathrm{C}_{3} \% \mathrm{Ao}+\mathrm{p}$ esquisa+bibliogr $\% \mathrm{C}_{3} \%$ Atfica:+guia+do+estudante+para+a+fund amenta $\% \mathrm{C}_{3} \% \mathrm{~A}_{7} \% \mathrm{C}_{3} \% \mathrm{~A}_{3} \mathrm{O}+\mathrm{do}+$ trabalho+de+pesquisa\&ots=SC_ j7mzxEF\&sig=TETECTdJRhrVTUZPD_dirW_ fkKo\# $\mathrm{v}=$ onepage\&q $=$ Inicia $\% \mathrm{C}_{3} \% \mathrm{~A}_{7} \% \mathrm{C}_{3} \% \mathrm{~A}_{3} \mathrm{\%} \% 20$ $\% \mathrm{C}_{3} \% \mathrm{Ao} \%$ 2opesquisa $\% 20$ bibliogr $\% \mathrm{C}_{3} \%$ A1fica $\% 3 \mathrm{~A} \% 20$ guia\%20do\%2oestudante\%2opara\%20a\%20 fundamenta $\% \mathrm{C}_{3} \% \mathrm{~A}_{7} \% \mathrm{C}_{3} \% \mathrm{~A}_{3} \mathrm{O} \% 2 \mathrm{Odo} \% 2$ trabalho $\% 20$ $\mathrm{de} \%$ 2opesquisa\&f=false. Acesso em: 23 nov. 2017. às 21:55.

MAGRO, C. B. D; RAUSCH R. B. Plano De Desenvolvimento Institucional De Universidades Federais Brasileiras.

Administração: Ensino e Pesquisa Rio De Janeiro, v. 13 n. 3, p. 427-454, 2012. Disponível em: https://raep.emnuvens.com. 
br/raep/article/view/85/167. Acesso em: 23 nov. 2017. às 21:57.

MEDEIROS, F. S. B. et al. O Comportamento dos Gastos Públicos em Educação no Munícipio de Santa Maria/RS. R. eletr. estrat. neg., Florianópolis, v. 6, n. 2, p. 128-156, 2013. Disponível em: http://portaldeperiodicos.unisul.br/index.php/ EeN/article/view/1283/1199. Acesso em: 23 nov. 2017. às 22:05.

OLIVEIRA, J. U. C. Estatística: uma nova abordagem. Rio de Janeiro: Ciência Moderna, 2010.

OTANI, N. et al. Diferenças entre o PDI e o Planejamento Estratégico na percepção dos Pis de Ies do segmento privado não universitário. XI Colóquio Internacional sobre Gestão Universitária na América do Sul, Florianópolis, 2011. Disponível em: https://repositorio.ufsc.br/ handle/123456789/26108. Acesso em: 20 nov. 2017. às 20:17.

PAZ, C., ALMEIDA, I., SILVA, E. Análise da Gestão do Programa Municipal de Apoio a Agricultura Familiar do Município de Urupá. Revista Eletrônica Saber Contábil - RSC, América do Norte, 2, mai. 2012. Disponível em: http://www.revista.ulbrajp.edu.br/ojs/index.php/contabeis/ article/view/1612/311. Acesso em: 23 nov. 2017. às 22:15.

PICAWY, Maria Maria. PDI - Plano de Desenvolvimento Institucional, PPI - Projeto Pedagógico Institucional e PPC Projeto Pedagógico de Curso, entre o dito e o feito, uma análise da implementação em três IES/RS/Brasil. Tese. (Doutorado) - Faculdade de Educação. Programa de Pós-Graduação em Educação. PUCRS, Porto Alegre, 2008. Disponível em: http:// hdl.handle.net/10923/2743. Acesso em: 23 nov. 2017 às 22:21.

RAMPAZZO, L. Metodologia científica: para alunos dos cursos de graduação e pós-graduação. 3. ed. São Paulo: Loyola, 2002.

REIS, Marcelo Menezes. Estatística aplicada à administração. Departamento de Ciências da Administração/UFSC, Florianópolis, 2008. Disponível em: http://arquivos.eadadm. ufsc.br/EaDADM/UAB_2014_2/Modulo_3/Estatistica/ material_didatico/Livro $\% 20$ texto $\% 20$ Estat $\% \mathrm{C}_{3} \%$ ADstica $\% 20$ Aplicada $\% 20 a \% 20$ Administra $\% \mathrm{C}_{3} \% \mathrm{~A}_{7} \% \mathrm{C}_{3} \% \mathrm{~A}_{3} \mathrm{O}$. pdf. Acesso em: 10 jun. 2018 às 16:00

SANTOS, J. L. S. et al. Modelo de Planejamento Estratégico em uma Universidade Pública Brasileira: Desenvolvimento e Implementação na Universidade Federal de Alagoas. IX Colóquio Internacional sobre Gestão Universitária na América do Sul. Florianópolis, 2009. Disponível em: https://repositorio.ufsc.br/xmlui/ 
handle/123456789/44283. Acesso em: 20 nov. 2017. às 20:12.

SILVA, M. C. Da. Demonstrações Contábeis Públicas:

Indicadores de desempenho e análise. São Paulo: Atlas, 2012.

STEVENSON, William J. Estatística aplicada à

administração. 1. ed. São Paulo: Harbra, 1981.

STEVENSON, William J. Estatística aplicada à administração. 3. ed. São Paulo: Harbra, 2001. 